\title{
The inventory and spore morphology of ferns from Bengkalis Island, Riau Province, Indonesia
}

\author{
NERY SOFIYANTI ${ }^{1, \bullet}$, MAYTA NOVALIZA ISDA ${ }^{1}$, ERWINA JULIANTARI $^{2}$, RISSAN SURIATNO ${ }^{1}$, \\ SYAFRONI PRANATA ${ }^{3}$ \\ ${ }^{1}$ Department of Biology, Faculty of Mathematics and Natural Sciences, Universitas Riau. Jl. Pekanbaru-Bangkinang Km 12.5, Kampus Bina Widya, \\ Simpang Baru, Panam, Pekanbaru 28293, Riau, Indonesia. Tel./fax.: +62-761-63273, vemail: nery.sofiyanti@lecturer.unri.ac.id \\ ${ }^{2}$ Plant Biology Graduate Program, Department of Biology, Faculty of Mathematics and Natural Sciences, Institut Pertanian Bogor. Jl. Raya Darmaga, \\ Bogor 16680, West Java, Indonesia \\ ${ }^{3}$ Ecology Division, Generasi Biologi Indonesia (Genbinesia) Foundation. J1. Swadaya Barat No. 4, Gresik 61171, East Java, Indonesia
}

Manuscript received: 8 September 2019. Revision accepted: 18 October 2019.

\begin{abstract}
Sofiyanti N, Isda MN, Juliantari E, Pranata S, Suriatno R. 2019. The inventory and spore morphology of ferns from Bengkalis Island, Riau Province, Indonesia. Biodiversitas 20: 3223-3236. Bengkalis Island is one of main islands at coastal region of Riau Province, Indonesia. The first fern inventory had been conducted on this island, to identify the fern checklist as well as examined the morphology of their spores. Samples were collected from 2 subdistricts and 12 study sites, using exploration method. The spore specimens were coated using AU, before observation using Scanning Electron Microscopy (SEM). A total of 22 fern species are recorded from Bengkalis Islands. These species belong to 3 orders, i.e. Gleicheniales (1 species), Polypodiales (20 species) and Schizaeales (1 species). The spore characteristic indicated similar unity of spore, i.e. monad spore, with triangular, subtriangular, tetrahedral and reniform shape. Three basic types of spore have been observed, i.e. monolete, dilete, and trilete. The spore class observed in this study are small $(22 \pm 0.88 \mu \mathrm{m})$, medium $(27.35 \pm 1.45$ to $47.85 \pm 0.88 \mu \mathrm{m})$ and large $(51.34 \pm 1.83$ to $53.8 \pm 1.81 \mu \mathrm{m})$. The ornamentation of perisphore is the main character to distinguished species within one genus.
\end{abstract}

Keywords: Bengkalis, fern, spore

\section{INTRODUCTION}

Fern and its allies are plant groups that characterized by having vascular bundles and spore (Kathleen and Rothwell 2001; Vasco et al. 2013). Fern is divided into two major groups, i.e. Eusporangiate ( $\mathrm{Hu}$ et al. 2016) and Leptosporangiate (Eric and Kathleen 2007). While the fern allies belong to Lycopod group (Lycopodiophyta) (LinkPerez and Laffan 2018) that characterized by its microphylls (White 1981) and the sporangia are arranged on the tip of stem form structure called strobilus (Pryer et al. 2004). Eusporangiate ferns differ from other fern groups in the sporangium that arise from several epidermis cells (Hu et al. 2016). Therefore, the sporangia have big size that forms a cluster called synangium, as found in Psilotum nudum (de la Torre and Osorio 2013). In contrast to the Eusporangiate ferns, the sporangium of leptosporangiate ferns arise from single epidermis cell and form a small sporangium. The sporangia will form a sorus that varies in size, shape, and position. Both Eusporangiate and Leptosporangiate ferns are placed in Polypodiophyta or Pteridophyta (Christenhusz and Chase 2014), and has higher number of species than Lycopodiophyta (Pryer et al. 2004; Schuettpelz and Pryer 2007). According to Christenhusz and Chase (2014) fern is consisted of 21 families with approximately 212 genera and 10.535 species.

The study of fern and its allies had been conducted intensively in Riau, Indonesia since 2010 to present, e.g. the studies on their morphology (Sofiyanti 2013;
Wulandari et al. 2016), micromorphology (Sofiyanti and Isda 2018), phytochemical (Yusna 2016; Wirdayanti and Sofiyanti 2019), anatomy (Sofiyanti et al. 2019ab), molecular approach (Sofiyanti and Isda 2019ab) and palynology (Marpaung et al. 2016; Sofiyanti 2019). The palynology is a study on the characteristic of pollen (for higher plant) and spore (for lower plant) that widely used to support taxonomic works of plants (Shah et al. 2019), classification (Vijayakanth and Sathis 2016) and evolution (Chao and Huang 2018). The spore features in fern have been applied in species delimitation, especially on exosphore and perisphore characters. The study on spore morphologies had been reported from many taxa of fern e.g. Anemia, Mohria, and Ceratopteris (Dettman and Clifford 1991); Oligocarpia (Wang et al. 1999), Davallia (Piñeiro and Morbelli 2012). For ferns from Sumatera, only limited taxa had been reported to their spore morphology. Marpaung et al. (2016) had studied on the spore of Pteridaceae from Rumbai Forest, Riau, while Sofiyanti (2019) reported the spore morphology of Aspleniaceae and Pteridaceae from some areas at coastal area of Riau.

Riau is a province located in northeast of Sumatra Island, Indonesia. From 2017 to 2018, fern explorations in the coastal area of Riau Province including Bengkalis Island have been conducted. The flora exploration in this island, particularly lower plant is very limited and no record of fern study had been previously reported from the island. Bengkalis island is located at the coast of Sumatera Island, it borders on the Bengkalis Strait to the west and 
Malacca strait to the north. This island is part of Bengkalis District, Riau Province, and comprises two subdistricts, Bengkalis and Bantan Subdistricts. The area is about 900 $\mathrm{km}^{2}$ with the maximum surface elevation ranges from 10 to $15 \mathrm{~m}$ asl. (Sutikno et al. 2017). Bengkalis Island has tropical climate and poses low topography relief. This study aimed to conduct inventory and examine the spore morphology of ferns from Bengkalis Island, Riau Province, Indonesia.

\section{MATERIALS AND METHODS}

\section{Study area}

This study had been conducted in Bengkalis Island, Riau Province, Indonesia from May to January 2018. Bengkalis Island is one of island in coastal region of Riau Province, Indonesia. The specimens were collected from 12 study sites as presented in Table 1. Figure 1 shows the map of Bengkalis Island.

\section{Procedures}

\section{Specimen collection}

The specimen collection had been carried out based on Reddy et al. (2012) using exploration method. All of the specimens were then photographed and followed by herbarium preparation. At least three specimens of each species were prepared for herbarium. The herbarium specimens were deposited at Herbarium Riauensis (HR), Department of Biology, Faculty of Mathematics and Natural Sciences, Universitas Riau, Pekanbaru, Indonesia.

\section{Species identification}

The identification of the species was done mainly based on Piggot (1998); Sofiyanti et al. (2015). Online identifications were also carried out using various websites. The accepted names were checked based on web http//:www.theplantlist.org.

\section{Spore observation}

Scanning Electron Microscope (SEM) spore observation was conducted based on Regalado and Saânchez (2002). The spore grains were collected from mature individuals in the field, stored in the zipped plastic bags before being observed. The spore specimens were put on the specimen holder and coated using gold $(\mathrm{Au})$. The specimens were then observed and photographed using ZEISS Scanning Electron Microscope EVO MA 10 (PT. Vanadia). Spore determination based on Erdtman (1957), Regalado and Sanchez (2002), Lashin (2012), and Wei and Dong (2012). At least 10 spore grains of each species were observed to provide the measurement data. In this study, a total of 22 fern species from Bengkalis Island species are identified. However, mature individuals from 5 out of 22 species were not found. Therefore, SEM observation of these 5 species was excluded, and the spore characterizations of these 5 species were based on the previous palynological studies.

Table 1. List of study sites in Bengkalis District, Riau Province, Indonesia

\begin{tabular}{lllll}
\hline $\begin{array}{l}\text { Sub- } \\
\text { district }\end{array}$ & No. & Study sites & Location & $\begin{array}{l}\text { Alt. } \\
(\mathbf{m})\end{array}$ \\
\hline Bengkalis & 1 & Bengkalis & Road Site & 14 \\
& 2 & Damon & Secondary forest & 14 \\
& 3 & Kelapa Pati & Roadside & 16 \\
& 4 & Sei Alam & Roadside & 16 \\
& 5 & Sengoro & Roadside & 17 \\
& 6 & Wonosari & Secondary forest & 15 \\
& 7 & Penebal & Roadside & 14 \\
Bantan & 8 & Bantan Air & Rubber forest & 16 \\
& 9 & Bantan Tengah & Secondary forest & 17 \\
& 10 & Bantan Tua & Roadside & 18 \\
& 11 & Resam Lapis & Secondary forest & 12 \\
& 12 & Selat baru & Roadside & 4 \\
\hline
\end{tabular}

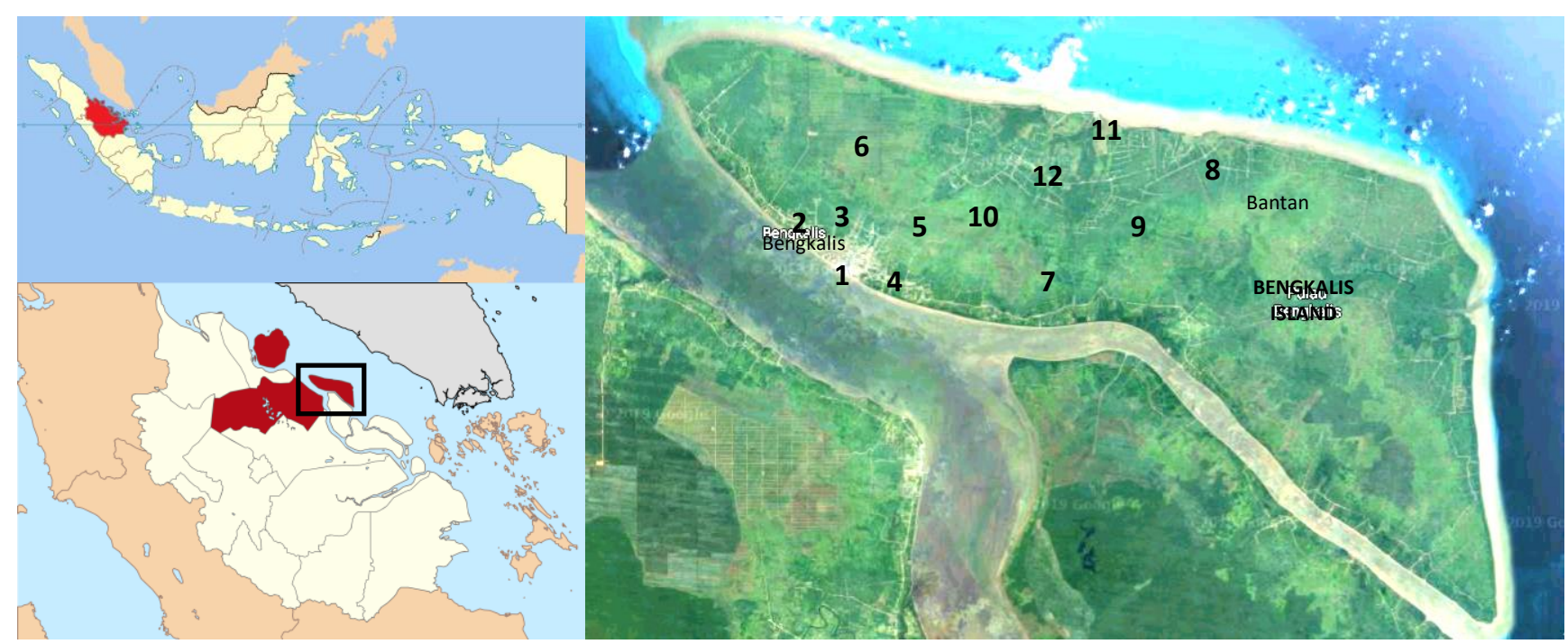

Figure 1. Location of Bengkalis Island, Bengkalis District, Riau Province, Indonesia (Numbers indicate study sites presented in Table 1) 


\section{Data analysis}

The result of fern inventory was tabulated and the morphological characters were analyzed descriptively. The spore morphologies were photographed, tabulated and also described.

\section{RESULTS AND DISCUSSION}

\section{The species diversity}

The inventory of ferns from Bengkalis Island identified a total of 22 fern species. All of the fern species belong to Division Polypodiophyta (Pteridophyta), class Polypodiopsida, with three orders i.e. Gleicheniales (1 species), Polypodiales (19 species) and Schizaeales (2 species). Table 2 presents the fern species identified in this study, while Figure 2 shows their morphologies. Specific characters are italicized in the description below.

\section{The enumeration of species \\ Glecheniales \\ Gleicheniaceae}

Dicranopteris linearis (Burm. f.) Underw. Bull. Torrey Bot. Club 34 (5): 250 1907; Fern of Malaysia n Color (1998); Morfologi Tumbuhan Paku di Taman Hutan Raya Sultan Syarif Hasyim Riau. (2015)

Description: Terrestrial. Creeping and climbing. Rhizome long, brown, hairy, hair black. Rachis dichotomous, branches near fork almost equal, light green. Monomorphic. Leaf stalk about $3 \mathrm{~cm}$ long, green. Laminae compound, up to $40 \mathrm{~cm}$ long or more, about $8 \mathrm{~cm}$ wide. Pinnae alternate, light green. Sori rounded, yellowish-green at juvenile and dark brown at maturity.

Examined specimens: DL BT1 Bantan Tua, DL BA1 Bantan Air, DL BKL1, Bengkalis, Riau, Indonesia. Nery \& Mayta.

Note: Habitat roadside, mainly at open-spaced area.

\section{Pteridales}

\section{Aspleniaceae}

Asplenium nidus L. Sp. Pl. 2: 1079 1753. Fern of Malaysia in Color (1998); Morfologi Tumbuhan Paku di Taman Hutan Raya Sultan Syarif Hasyim Riau. (2015)

Description: Epiphyte, rarely lithophyte. Rhizome short, stout, dark brown, scaly. Scale dark brown, $2 \mathrm{~cm}$ or more. Stipes dark brown to almost black, ca. 5-6 cm long or more, scaly at the base. Fronds in rosette arrangement, forming a bird nest-shaped, ca. $2.5-3 \mathrm{~m}$ or more in diameter at maturity, simple, ca. $130 \mathrm{~cm}$ long or more, up to $20-25 \mathrm{~cm}$ broad or more, linear with broadest at the middle, gradually narrowing towards apex and towards base. Young fronds from fiddlehead, pale green. Sori elongated at both sides of costa, along veins, dark brown when mature.

Examined specimens: AN RL1, RL2 Resam Lapis, Bantan, Riau, Indonesia. Nery \& Mayta.

Note: Commonly found as epiphytic fern at various tree species, e.g. Rambutan tree.
Asplenium longissimum Blume. Fern of Malaysia in Color (1998).

Description: Terrestrial. Rhizome shorts almost black, erect or suberect, scaly. Scale dark brown to blackish brown, entire. Stipes up to $25 \mathrm{~cm}$ long or more, dark purple to blackish purple, scaly at juvenile. Laminae up to $140-$ $150 \mathrm{~cm}$ long or more, about $15 \mathrm{~cm}$ broad, pinnate, sometimes bear a bulbil on rachis near the apex of frond. Bulbils grow to a new individual when reach a suitable substrate. Pinnae dark green, up to 50 pairs in a lamina, shortly stalked, base broader, ascending, gradually narrowed toward apex, margin lobed, tip acuminate, up to 7 $\mathrm{cm}$ long or more, up to $1.5 \mathrm{~cm}$ broad. Rachis grooved from the base to apex, blackish-purple, scaly. Sori elongated at both sides of costae, little curved at the apex. Indusia present.

Examined specimen: AL RL1, RL2, RL3, Resam Lapis, Bantan,

Note: commonly found as lower flora at Rubber Forest.

\section{Blechnaceae}

Stenochlaena palustris (Burm. F.) Bedd. Ferns Brit. India (Suppl.): 26, t. 201 1876. Fern of Malaysia n Color (1998); Morfologi Tumbuhan Paku di Taman Hutan Raya Sultan Syarif Hasyim Riau. (2015).

Description: Terrestrial. Rhizome long, creeping or climbing on the tree trunk or other flora, green. Dimorphic. Sterile fronds up to $75 \mathrm{~cm}$ long or more, reddish-brown at the juvenile, become green at maturity. Stipes of sterile fronds about $20 \mathrm{~cm}$ long or more, rounded, green. Sterile laminae pinnate, bearing about 15 pairs of lateral pinnae or more, opposite. Sterile pinnae shortly stalked, cuneate at the base, margin serrate, acuminate at the base, glossy dark green, ca. $14-15 \mathrm{~cm}$ long or more, ca. 3.5-4 $\mathrm{cm}$ broad or more. Fertile frond up to $100 \mathrm{~cm}$ or more, yellowish-green at the juvenile, become dark brown at maturity. Stipes of fertile fronds green, up to $30 \mathrm{~cm}$ long or more. Fertile laminae pinnae, bearing about 17 pairs of lateral pinnae. Fertile lateral pinnae linear, up to $25 \mathrm{~cm}$ long or more, 4 $\mathrm{mm}$ broad, dark brown. Sori acrostichoid, covering the whole of dorsal side of fertile pinnae.

Examined specimens: SP SB1 Selat Baru, Bantan; SP BKL2, SP BKL3, Bengkalis, SP DA1 Damon, Bengkalis, Riau, Indonesia. Nery \& Mayta.

Note: widely distributed at roadside, open-spaced area, forest floor.

Blecnum serrulatum Rich. Actes Soc. Hist. Nat. Paris 1: 1141792 .

Description: Terrestrial, especially at open-spaced area. Rhizome short and erect, scaly. Scale brown at the base and bright brown toward apex. Stipes brownish green and scaly at the base, light green toward apex, stramineous, 25-35 $\mathrm{cm}$. Laminae dark green, up to 45 or more by $15-20 \mathrm{~cm}$, wider in the middle, apex acute. Pinnae slightly ascending, up to 28 pair or more, linear, margin serrate, $14-16 \mathrm{~cm}$ by ca. $1.5 \mathrm{~cm}$, narrower at soriferous pinnae. Sori linear, along the costae of pinnae, dark brown and thick. 
Table 2. List of identified species in this study

\begin{tabular}{|c|c|c|c|}
\hline Order-Family & No. & Species & Vernacular name \\
\hline \multicolumn{4}{|l|}{ Gleicheniales } \\
\hline Gleicheniaceae & 1 & Dicranopteris linearis (Burm. f.) Underw. & Paku resam \\
\hline \multicolumn{4}{|l|}{ Polypodiales } \\
\hline \multirow[t]{2}{*}{ Aspleniaceae } & 2 & Asplenium nidus $\mathrm{L}$. & Paku sarang burung \\
\hline & 3 & Asplenium longissimum Blume. & Not known \\
\hline \multirow[t]{3}{*}{ Blechnaceae } & 4 & Stenochlaena palustris (Burm. f.) Bedd.* & Paku miding \\
\hline & 5 & Blechnum serrulatum Rich. & Paku pantai \\
\hline & 6 & Blechnum sp. & \\
\hline Davalliaceae & 7 & Davallia denticulata (Burm. f.) Mett. ex Kuhn & Paku \\
\hline Dennstaedtiaceae & 8 & Pteridium caudatum (L.) Maxon.* & Paku \\
\hline Lindsaeaeceae & 9 & Lindsaea ensifolia $\mathrm{Sw}$. & Paku \\
\hline \multirow[t]{2}{*}{ Nephrolepidaceae } & 10 & Nephrolepis hirsutula (G. Forst) C. Presl & Paku uban \\
\hline & 11 & Nephrolepis bisserata (Sw.) Schott & Paku uban \\
\hline \multirow[t]{3}{*}{ Polypodiaceae } & 12 & Microsorum punctatum (L.) Copel, & Paku \\
\hline & 13 & Pyrrosia piloselloides (L.) M.G. Price & Paku sisik naga \\
\hline & 14 & Phymatosorus scolopendria Burm. f.) Pic. Serm. & Paku \\
\hline \multirow[t]{5}{*}{ Pteridaceae } & 15 & Acrostichum aureum $\mathrm{L}$. & Paku laut \\
\hline & 16 & Ceratopteris thalictroides (L.) Brongn* & Paku air \\
\hline & 17 & Pteris vitata $\mathrm{L}$. & Pakis tanah \\
\hline & 18 & Vittaria elongata SW.* & Paku sawit \\
\hline & 19 & Vittaria ensiformis Sw. Kaulf* & Paku sawit \\
\hline Thelypteridaceae & 20. & Pronephrium sp. & Paku \\
\hline \multicolumn{4}{|l|}{ Schizaeales } \\
\hline \multirow[t]{2}{*}{ Lygodiaceae } & 21 & Lygodium microphyllum (Cav.) R. Br. & Paku rambat \\
\hline & 22 & Lygodium japonicum (Thumb.) SW.* & Paku rambat \\
\hline
\end{tabular}

Note: * No mature individuals found from the field, and excluded for SEM observation

Examined specimens: BS SB1-3, Selat Baru, Bantan, Riau, Indonesia. Nery \& Mayta.

Note: Habitat in coastal area, open-spaced.

\section{Blechnum sp.}

Description: Terrestrial, especially at open-spaced area. Rhizome short and erect, scaly. Scale brown at the base and bright brown toward apex. Stipes brownish green and scaly at the base, light green towards apex, stramineous, 25-35 $\mathrm{cm}$. Laminae reddish-green at juvenile, green at maturity, up to $60 \mathrm{~cm}$ long or more by $20-25 \mathrm{~cm}$, wider in the middle, apex acute. Pinnae alternate, wider in the middle and gradually narrowed towards apex, up to 30 pair or more, almost ellipsoid, margin serrate, $15-17 \mathrm{~cm}$ by 3-4 $\mathrm{cm}$.

Examined specimens: BSP BKL1, BSP BKL2, BSP BKL3, Kelapa Pati, Bengkalis, Riau, Indonesia. Nery \& Mayta.

Note: rarely found on the island, at openspaced/roadside.

\section{Davalliaceae}

Davallia denticulata (Burm. f.) Mett. ex Kuhn. Filic. Afr. 27 1868. Fern of Malaysia in Color (1998); Morfologi Tumbuhan Paku di Taman Hutan Raya Sultan Syarif Hasyim Riau. (2015).

Description: Epiphyte. Rhizome long and creeping, light brown, scaly. Scale dense, ovate at the bae, brown. Dimorphic, sterile frond and fertile frond at different stipes. Sterile stipe brown, up to $20 \mathrm{~cm}$ long or more. Sterile laminae subtriangular, green, gradually narrowing towards apex, broadest at the base, up to $40 \mathrm{~cm}$ long or more, up to $30 \mathrm{~cm}$ broad or more. Sterile pinnae green, anadromous, subtriangular at the base. Sterile pinnules stalked, oblong, acute to acuminate, margin lobe. Fertile laminae subtriangular, green, gradually narrowing towards apex, base broader, $35-50 \mathrm{~cm}$ long or more, ca. $25-35 \mathrm{~cm}$ broad. Fertile pinnae green, anadromous, subtriangular at the base. Sterile pinnules stalked, oblong, acute to acuminate, margin lobed bearing sori. Sori at the lobe margin, small with cupshaped indusia.

Examined specimens: DD SA1 Sei Alam, DD SE1 Senggoro, DD PE1 Penebal, Bengkalis; DD BT1 Bantan Tengah, Bantan, Riau, Indonesia. Nery \& Mayta.

Note: found as epiphytic fern at Rambutan tree, Rubber Tree and oil palm tree.

\section{Identification key}

1a. Rachis unbranched or linear f..................................... 2

1b. Rachis dichotomous, branches near fork almost equal, Laminae compound, up to $40 \mathrm{~cm}$ long or more; sori rounded, yellowish-green at juvenile and dark brown at maturity Dicranopteris linearis

2a. Sporangia at the lower surface of lamina or pinna; or at the leaf margin .......................................................... 3

2b. Sporangia at the lobes of leaf margin form sorophore ...... 21

3a. Sporangia at the lower surface of lamina or pinna ............. 4

3b. Sporangia at the leaf margin, inside cup-shaped indusia ................................. Davallia denticulata 

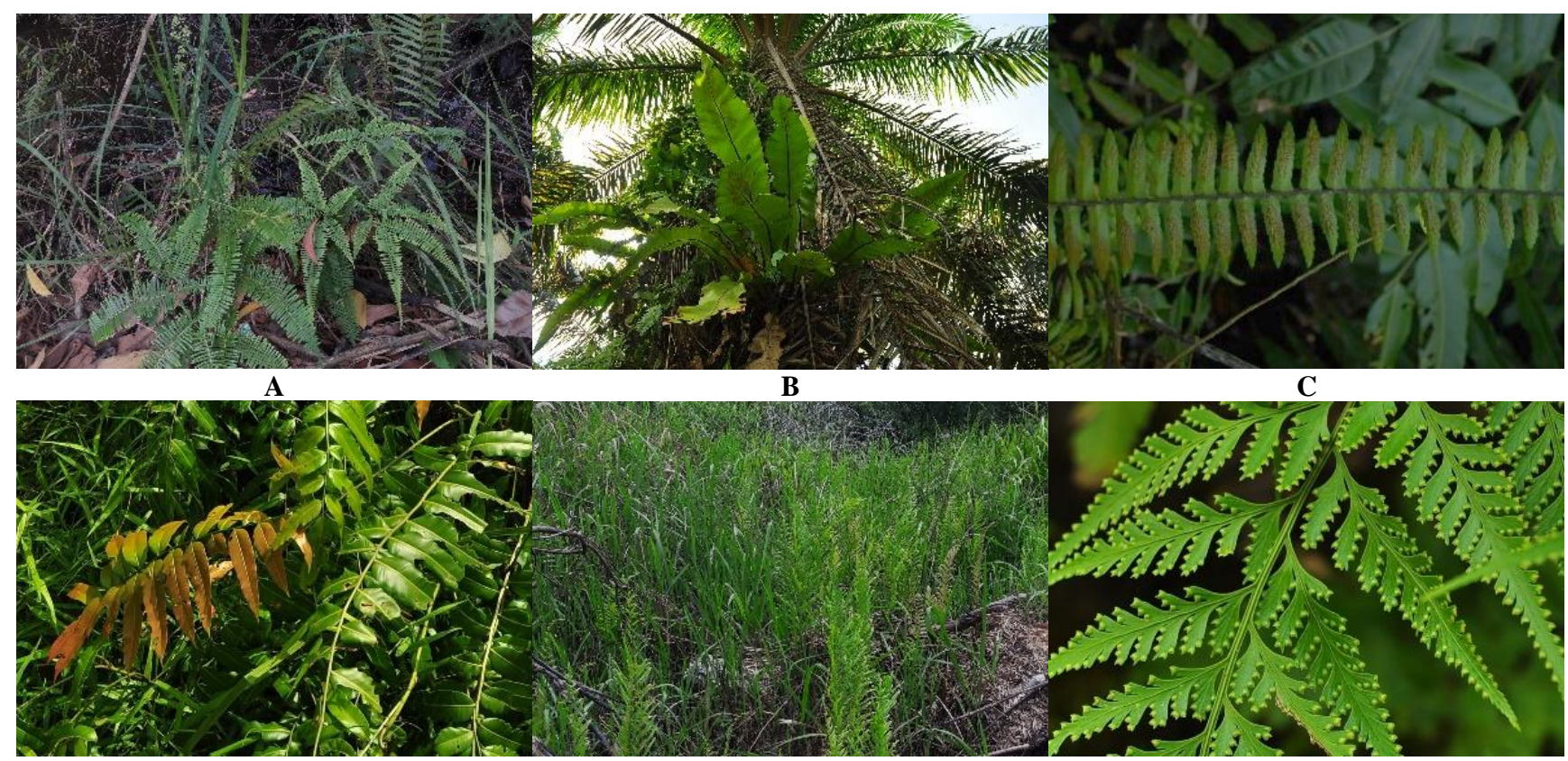

B
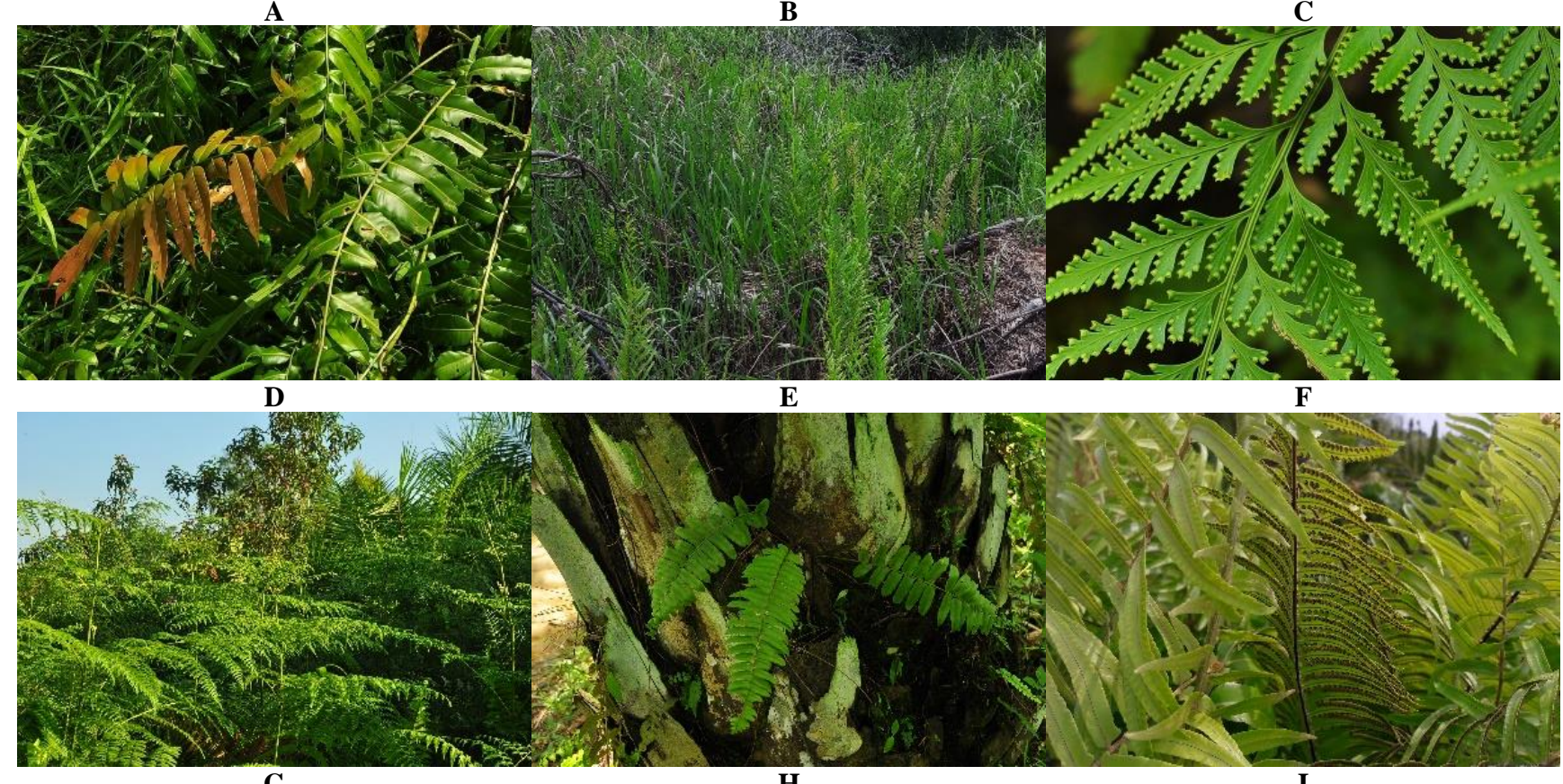

$\mathbf{G}$

H

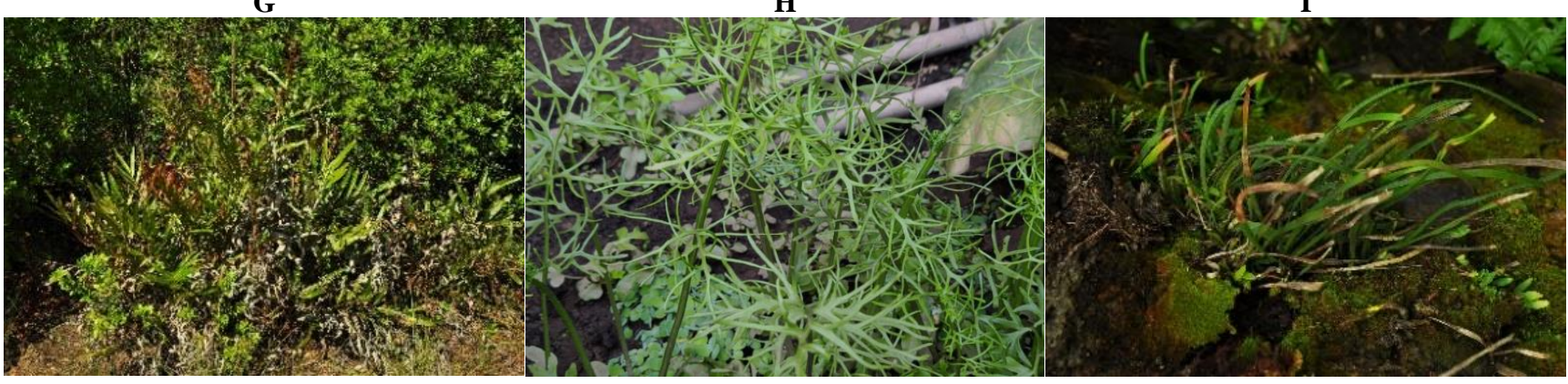

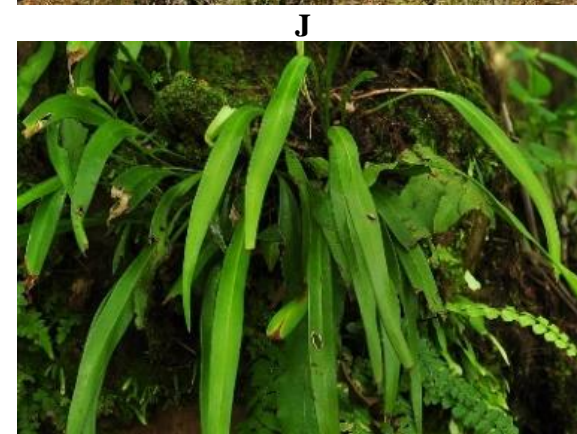

M
K

L

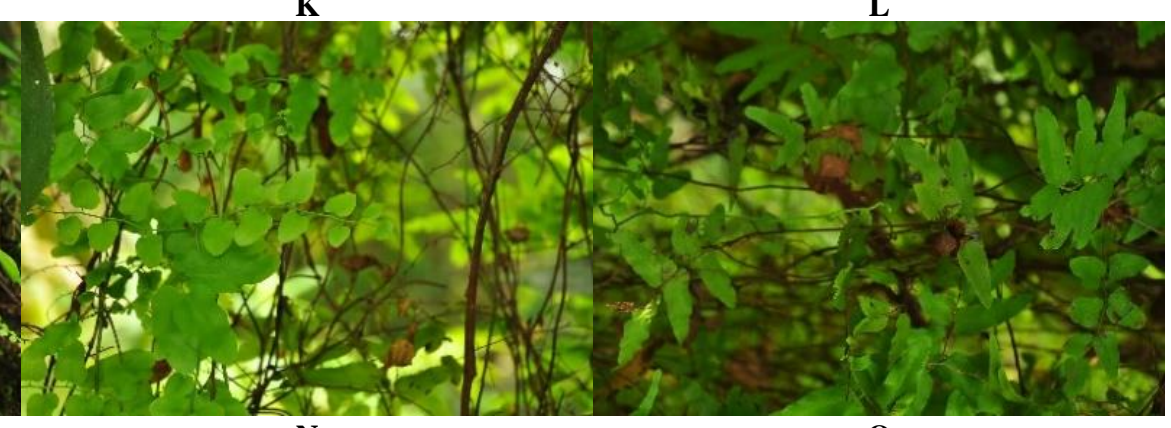

N

Figure 2. Morphologies of ferns from Bengkalis Island, Riau Province, Indonesia. A Dicranopteris linearis, B. Asplenium nidus, C Asplenium longissimum, D Stenochlaena palustris, E. Blechnum serrulatum, F. Davallia denticulata, G. Pteridium caudatum, H. Nephrolepis biserrata, I. Nephrolepis hirsutula, J. Acrostichum aureum, K. Ceratopteris thalictroides, L. Vittaria elongata, M. Vittaria ensiformis, N. Lygodium microphyllum, O. Lygodium japonicum 
4a. Sori elongated at the midrib or leaf margin or acrostichoid ................................................................. 5

4b. Sori rounded at lower surface of leaf, or linear forming parallel structure ..... 13

5a. Sori elongated at the midrib or leaf margin

5b. Sori acrostichoid forming linear lamina Stenochlaena palustris

6a. Sori elongated on both side of midrib 7

6b. Sori linear along the leaf margin 8

7a. Height ca. 40-50 cm, young laminae green, sori thick ..................................................... Blechnum serrulatum

7b. Height ca. $75 \mathrm{~cm}$, young laminae reddish-brown, sori thin Blechnum sp.

8a. Laminae linear or lobed, single or compound

8b. Laminae stem-like ca. $2 \mathrm{~mm}$ wide

Ceratopteris thalictroides

9a. Laminae compound 10

9b. Laminae single 12

10a. Height 40-50 cm; laminae pinnate; pinnae linear broader at the base, margin entire

10b. Height up to $200 \mathrm{~cm}$; laminae tripinnate; pinnae triangular, pinnule margin lobed ......... Pteridium caudatum

11a. Pinnae light green, not glossy, facing upward ... Pteris vittata

11b. Pinnae dark green, glossy ................. Lindsaea ensiformis

12a. Young and mature laminae light green, ca. $50 \mathrm{~cm} \times 2$ $\mathrm{mm}$.................................................... Vittaria elongato

12b. Young laminae bright red on the top and gradually become green toward base, mature laminae dark green, ca. $40 \mathrm{~cm}$ x $4 \mathrm{~mm}$ Vittaria ensiformis

13a. Sori rounded at lower surface of leaf 14

13b. Sori linear forming parallel structure

20

14a. Monomorphic or dimorphic, young laminae green ........... 15

14b. Semidimorphic, young laminae reddish-brown Acrostichum aureum

15a. Monomorphic 16

15b. Dimorphic 17

16a. Epiphyte. Laminae single, up to $125 \mathrm{~cm}$ long, linear, margin slightly wavy, sori small and numerous Microsorum punctatum

16b. Terrestrial. Laminae pinnate, up to $50 \mathrm{~cm}$, upper pinna longer Phroneprium sp.

17a. Laminae compound, papery

17b. Laminae single, fleshy; sterile laminae oval, ca. $3 \mathrm{x}$ $1.3 \mathrm{~cm}$; fertile laminae longer ca. $105 \times 1 \mathrm{~cm}$ Pyrrosia piloselloides

18a. Rhizome short, brown, scally; scale brown; young frond densely covered by white hair; laminae linear, hairy

18b. Rhizome long, green, scaly; scale black to brown; young frond sparsely covered by brown hair; lamina polymorph, single, or deeply lobed 19a. Laminae up to $140 \mathrm{~cm}$ long, pinnae elongated up to 15 $\mathrm{x} 1 \mathrm{~cm}$. . Nephrolepis hirsutula

19b. Laminae up to $90 \mathrm{~cm}$ long, pinnae up to $10 \times 1.3 \mathrm{~cm}$, broader in the middle.... Nephrolepis biserrata

20a. Laminae single, up to $200 \mathrm{~cm}$ long or more arranged in rosette, stipe short, brownish-black ....... Asplenium nidus

20b. Laminae pinnate, ca. $100 \mathrm{~cm}$ long forming bulbil on the tip; stipe up to $20 \mathrm{~cm}$ or more, purplish-black Asplenium longissimum

21a. Pinnulae small, almost rounded, ca. $1 \times 1 \mathrm{~cm}$ Lygodium microphyllum

21b. Pinnae deltoid, base broader, narrower toward apex, ca. 2-3 x 1.3, terminal pinnula trilobed, longer at the tip apex almost rounded Lygodium japonicum

\section{Dennstaedtiaceae}

Pteridium caudatum (L.) Maxon. Proc. U.S. Natl. Mus. 23 (1226): 631 1901. Fern of Malaysia in Color (1998); Morfologi Tumbuhan Paku di Taman Hutan Raya Sultan Syarif Hasyim Riau. (2015)

Description: Terrestrial. Rhizome long creeping, hairy. Hair light brown. Stipes long, up to $100 \mathrm{~cm}$ long or more, dark brown or blackish brown, hairy. Rachis dark brown, grooved at upper surface. Laminae pinnate, at the base quadripinnatifid, broadest at the base, subtriangular, up to $100 \mathrm{~cm}$ long, ca. $90 \mathrm{~cm}$ broad. Lateral pinnae: base larger up to $75 \mathrm{~cm}$ long, $35 \mathrm{~cm}$ broad or more. Sori almost at the margin, linear. Indusia present

Examined specimens: PD BKL1 Selat Baru, Bantan, PD BKL2, PD BKL3, Resam Lapis, Bantan, PD BKL4 Bengkalis, Riau, Indonesia. Nery \& Mayta.

Note: commonly found at roadside, open-spaced area.

\section{Lindsaeaeceae}

Lindsaea ensifolia SW. J. Bot. (Schrader 1800 (2): 77 1801. Fern of Malaysia n Color (1998); Morfologi Tumbuhan Paku di Taman Hutan Raya Sultan Syarif Hasyim Riau. (2015)

Description: Terrestrial. Rhizome creeping, brown to dark brown, scaly. Scale linear. Stipes dark brown, castaneous bearing pinnate laminae. Laminae simply pinnate, sometimes simple, ovate to oblong, alternate, up to $30 \mathrm{~cm}$ or more. Pinnae dark green, up to $15 \mathrm{~cm}$ long or more, up to $1.5 \mathrm{~cm}$ broad, arranged in $2-3 \mathrm{~cm}$ apart from other pinnae, linear, shortly stalked, almost rounded at the base, margin entire, veins anastomosing. Sori linear, continuous along pinna margin

Examined specimens: LE BKL1, LE BKL2, LE BKL3, Bantan Air, LE BKL4 Bengkalis, Riau, Indonesia. Nery \& Mayta.

Note: Commonly found at shady area, solitary.

\section{Nephrolepidaceae}

Nephrolepis hirsutula (G. Forst) C. Presl. Tent. Pterid. 79 1836. Fern of Malaysia n Color (1998); Morfologi Tumbuhan Paku di Taman Hutan Raya Sultan Syarif Hasyim Riau. (2015) 
Description: Terrestrial or epiphyte. Rhizome short erect or suberect, densely scaled, dark brown to pale brown. Young frond hairy. Hair almost white to light brown. Stipes up to $35 \mathrm{~cm}$ or more, about $8 \mathrm{~mm}$ in diameter, scaly. Laminae up to $60 \mathrm{~cm}$ or more, about $20 \mathrm{~cm}$ broad, simply pinnate, bearing up to 50 pairs of lateral pinnae or more. Lateral pinnae alternate, located about 2.5 $\mathrm{cm}$ apart from upper pinnae light green, covered by short hair, elongated, apex curved downward, up to $15 \mathrm{~cm}$ long or more, about $1.5 \mathrm{~cm}$ broad. Margin lobed. Sori rounded, regularly arranged at the margin of lower surface of pinnae. Indusia present, reniform.

Examined specimens: NH BKL1, NH BKL2, NH BKL3, Bantan, NH BKL4, NH 5 BKL Bengkalis, Riau, Indonesia. Nery \& Mayta.

Note: Found at various habitat as terrestrial, epiphytic or lithophytic fern.

Nephrolepis biserrata (Sw.) Schott. Gen. Fil. pl. 3 1834. Fern of Malaysia n Color (1998); Morfologi Tumbuhan Paku di Taman Hutan Raya Sultan Syarif Hasyim Riau. (2015)

Description: Terrestrial or epiphyte. Rhizome short erect or suberect, densely scaled, dark brown to pale brown. Young frond hairy. Hair almost white to light brown. Stipes up to $25 \mathrm{~cm}$ or more, about $7 \mathrm{~mm}$ in diameter, scaly. Laminae up to $50 \mathrm{~cm}$ or more, about $17 \mathrm{~cm}$ broad, simply pinnate, bearing up to 40 pairs of lateral pinnae or more. Lateral pinnae alternate, densely arranged in rachis, light green, covered by short hair, apex curved downward, up to $20 \mathrm{~cm}$ long or more, about $2 \mathrm{~cm}$ broad. Sori rounded, regularly arranged at the lower surface of pinnae. Indusia present, reniform.

Examined specimens: NB BKL1, Nb BKL2, Nb BKL3, Bantan, Nb BKL4, NB 5 BKL Bengkalis, Riau, Indonesia. Nery \& Mayta.

Note: Found at various habitat as terrestrial, epiphytic or lithophytic fern.

\section{Polypodiaceae}

Microsotum punctatum (L.) Copel. Univ. Calif. Publ. Bot. 16 (2): 1111929.

Description: Epiphyte. Rhizome dark brown, creeping, scaly. Fronds simple, closely spaced, ca. 100-120 cm long $\mathrm{x}$ ca. $15 \mathrm{~cm}$ broad; midrib raised. Laminae margin revolute. Sori small, numerous and round. Stipe short or undistinct with laminae, brownish-black. Laminae simple, lanceolate, gradually narrower toward base and apex, up to $110 \mathrm{~cm}$ long by ca. $16 \mathrm{~cm}$ wide, light green. Costae raised, brownish-black.

Examined species: MP BKL1 Bantan, Bengkalis, Riau, Indonesia. Nery \& Mayta.

Note: Rarely found, epiphytic fern.

Pyrrosia piloselloides (L.) M.G. Price Kalikasan 3: 176 1975. Fern of Malaysia n Color (1998); Morfologi Tumbuhan Paku di Taman Hutan Raya Sultan Syarif Hasyim Riau. (2015)

Description: Epiphytic. Rhizome long, creeping, up to 1 $\mathrm{mm}$ in diameter, scaly, dark brown to brownish-black. Dimorphic, sterile frond and fertile frond on the different stipes. Fronds about 1,5-3,5 cm apart. Sterile fronds: shortly stalked; stalk brown, laminae almost circular, margin entire, apex rounded, dark green, about $1 \times 2 \mathrm{~cm}$ in size. Fertile fronds: shortly stalk, linear, margin entire, apex rounded, ca. $15-20 \mathrm{~cm}$ long x $1 \mathrm{~cm}$ broad. Sori thick, continuous at the margin of laminae. Dark brown at maturity.

Examined specimens: PP BKL1, PP BKL2, PP BKL3, Bantan, PP BKL4, PP 5 BKL Bengkalis, Riau, Indonesia. Nery \& Mayta.

Note: rarely found, epiphytic fern at Mango tree (Mangifera indica).

Phymatosorus scolopendria (Burm. f.) Pic. Serm.. Webbia 28 (2): 457, 4601973.

Description: Epiphyte. Rhizome creeping, dark green with whitish part, scaly. Fronds closely spaced, gradually narrowing from basal to apex. Laminae oblong to lanceolate, various shapes, margin lobed or revolute, up to $100 \mathrm{~cm}$ long. Sori rounded, small, numerous.

Examined specimens: PS BKL1, PS BKL2 Wonosari, Bengkalis, Riau, Indonesia. Nery \& Mayta.

Note: Rarely found. Epiphytic fern at stem of Oil Plam tree.

\section{Pteridaceae}

Acrostichum aureum L. Sp. Pl. 2: 10691753.

Description: Terrestrial, including the in wet area. Rhizome thick, erect, scally, dark brown. Fronds imparipinnate, ca. 2-3 cm long or more. Stipes up to $1 \mathrm{~m}$ long or more, thick. Rachis thick, dark brown, bearing sterile pinnae at lower part and fertile pinnae on the top portion. Lateral pinnae brownish red at juvenile, ascending, stalked (about $2 \mathrm{~cm}$ long), narrowly oblong, rounded or irregular at the base, rounded to refuse shortly mucronate at apex, entire, glabrous. Costa grooved above while veins raised below. Fertile pinnae, smaller than steril pinnae. Sporangia scattered and cover the whole of under surface.

Examined specimens: AA SB1-4, Selat Baru, Bantan, Bengkalis, Riau, Indonesia. Nery \& Isda.

Note: widely distributed in coastal area, form dense population.

Ceratopteris thalictroides (L.) Brongn. Bull. Sci. Soc. Philom. Paris 8: 1861821.

Description: Rhizome erect. Frond dimorphic, erect, light green, up to $50 \mathrm{~cm}$ tall or more. Stipes fleshy up to 35 $\mathrm{cm}$ long. Sterile laminae bipinnatifid, shorter than fertile laminae, pinna wider that fertile lainane; fertile laminae longer, up to $50 \mathrm{~cm}$ or more, copiously divided, pinnule linea with acuminatus apex, stem-like.

Examined specimens: CT BKL1, CT BKL2, Bengkalis, Riau, Indonesia. Nery \& Mayta.

Note: rarely found on the island, habitat at wet soil, or flooded areas.

Pteris vittata L. Sp. Pl. 2: 10741753.

Description: Terrestrial. Rhizome short, erect, scaly. Stipe up to $25 \mathrm{~cm}$, densely scaly. Laminae imparipinnate; 
pinnae simple, broader at the base, apex acuminate, margin serrate, terminal pinnae much longer. Sori marginal, along the pinnae margin.

Examined specimens: PV BKL1, PV BKL2, PV BKL3, Bantan, PV BKL4, PV BKL Bengkalis, Riau, Indonesia. Nery \& Mayta.

Note: rarely found, terrestrial and sometime lithophyte.

Vittaria elongata Sw. Syn. Fil. 109, 302 1806. Fern of Malaysia in Color (1998); Morfologi Tumbuhan Paku di Taman Hutan Raya Sultan Syarif Hasyim Riau. (2015)

Description: Epiphyte. Rhizome short, creeping, scaly. Scale of rhizome brown, lanceolate. Frond simple, stipes absent, young frond light green forming fiddlehead, linear to oblong, up to $35 \mathrm{~cm}$ long or more, about $1,5 \mathrm{~cm}$ broad, broadest at the middle, margin entire. Vein linear. Sori linear at the margin of laminae, dark brown at the maturity.

Examined specimens: VEL BKL1, VEL BKL2, VEL BKL3, Bantan, VEL BKL4, VEL5 BKL Bengkalis, Riau, Indonesia. Nery \& Mayta.

Note: rarely found, epiphytic at stem of Oil Palm Tree

Vittaria ensiformis Sw. Kaulf. Ges. Naturf. Freunde Berlin Neue Schriften 2: 134, pl. 7, f. 1 1799. Fern of Malaysia in Color (1998); Morfologi Tumbuhan Paku di Taman Hutan Raya Sultan Syarif Hasyim Riau. (2015)

Description: Epiphytic. Rhizome short, creeping, scaly. Scale of rhizome brown, lanceolate. Frond simple, stipes absent, young frond red at the apex, gradually green toward base, mature fronds dark green, apex brown when dry, linear, up to $30 \mathrm{~cm}$ long or more, about $5 \mathrm{~mm}$ broad, margin entire. Vein not clear. Sori linear at the margin of laminae, dark brown at the maturity.

Examined specimens: VE BKL1, VE BKL2, VE BKL3, Bantan, VE BKL4, PP 5 BKL Bengkalis, Riau, Indonesia. Nery.

Note: rarely found, epiphytic at stem of Oil Palm Tree

\section{Thelipteridaceae}

\section{Pronephrium sp.}

Description: Epiphytic. Rhizome long, climbing. Frond scaly at juvenile, stipe dark brown, up to $30 \mathrm{~cm}$ long; rachis long, linear up to $100 \mathrm{~cm}$ or more. Lamina bipinnatifid, ca. $20 \mathrm{~cm}$ broad. Pinnae papery, densely covered by white hair, oblong, apex acuminate, margin entire, ca. 20 x $5 \mathrm{~cm}$ terminal pinna much longer up to $30 \mathrm{~cm}$ or more.

Examined specimens: PRO BKL1, PRO BKL2, Damon, Bengkalis, Riau, Indonesia. Nery. Tree

Note: rarely found, epiphytic fern at stem of Oil Palm

\section{Schizaeales}

Lygodiaceae

Lygodium microphyllum (Cav.) R. Br. Hort. Berol. 2. 141 1833. Fern of Malaysia in Color (1998); Morfologi
Tumbuhan Paku di Taman Hutan Raya Sultan Syarif Hasyim Riau. (2015)

Description: Epiphyte or terrestrial. Rhizome creeping, climbing, branches irregular. Dimorphic, sterile frond and fertile frond on the different stipes. Fronds about $1 \mathrm{~cm}$ apart. Sterile fronds pinnae, bearing up to 11 pinnae or more. Sterile pinnae almost subtriangular to oblong, margin entire, apex rounded, green, about $2 \mathrm{~cm}$ long or more, $1 \mathrm{~cm}$ broad, broadest at the base, apex rounded, margin entire. Fertile pinnae, almost rounded, broadest at the base, margin covered by sporangia. Sporangia at the lobes of leaf margin, forming sorophore. Indusia present, serrate at the margin.

Examined specimens: VE BKL1, VE BKL2, VE BKL3, Bantan, VE BKL4, PP 5 BKL Bengkalis, Riau, Indonesia. Nery fern

Note: commonly found at open spaced area, climbing

Lygodium japonicum (Thunb.) Sw. J. Bot. (Schrader) 1061802.

Description: Epiphyte or terrestrial. Rhizome creeping, climbing, branches irregular. Dimorphic. Fronds climbing; stipe up to $20 \mathrm{~cm}$ or more; laminae tripinnatifid; primary rachis distinct, ca. $16 \mathrm{~cm}$ long; secondary rachis up to 20 $\mathrm{cm}$ long, pinnae numerous, deltoid, ca. $2-3 \times 1.3 \mathrm{~cm}$, base broader, narrower toward apex, margin biserrate, terminal pinnula trilobed, longer at the tip; apex almost rounded. Sporangia-bearing lobes at the margin of pinnula, forming sorophore that smaller than sterile pinnula.

Examined specimens: LJ BKL1, LJ BKL2, LJ BKL3, BKL Resam Lapis, Bantan, Riau, Indonesia. Nery \& Mayta. fern

Note: commonly found at open spaced area, climbing

\section{Spore morphology}

In fern, spore grains are located inside the sporangium that clustered together forming synangium (Pšenička et al. 2009), strobilus (Pryer et al. 2004) or sorus (Hugh et al. 2011). The spore morphology of fern is unique among the species. Therefore, it plays an important role in its taxonomic works, e.g. for identification and classification. In this study, SEM observation had been conducted on a total of 18 out of 22 fern species. The previous studies on spore morphology of related species to complete spore feature discussion were used. Figures 3, 4 and 5 present the spore morphology of examined fern species, while Table 3 presents the spore features. All of the species examined in this study show monad spore unity, in which the spores are released in the single grain. Monad type is also found in pollen of higher plants as reported on Rafflesia (Sofiyanti et al. 2012), Acacia (Al-Watban et al. 2013), Aster (Salamah et al. 2019). 


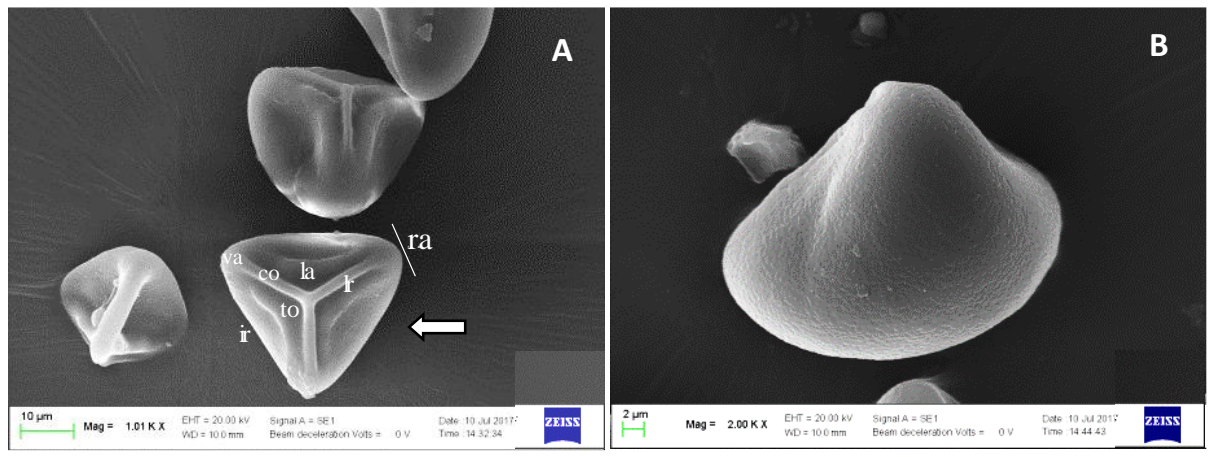

Figure 3. SEM image of fern Dicranoteris linearis spore (Glecheniales, Glecheniaceae) OF Bengkalis Island, Riau Province, Indonesia. A. Spore grains in different view, arrow is showing proximal view of spore with triangular shape (radial symmetry) and trilete aperture, B. Distal view showing spore surface with psilate ornamentation $(\mathrm{ra}=$ radial area, $c o=$ commissure, ir $=$ interradial, $l \mathrm{la}=\mathrm{labrum}, \mathrm{l} \mathrm{r}=$ laesura radii, to $=$ torus, $v a=$ valva).

Table 3. Spore features of ferns from Bengkalis Island, Riau Province, Indonesia

\begin{tabular}{|c|c|c|c|c|c|c|}
\hline Species & $\begin{array}{l}\text { Spore unity-shape } \\
\text { of equatorial view }\end{array}$ & Basic type-aperture-perisphore & $\begin{array}{c}\mathbf{P} / \mathbf{E} \\
\text { Ratio }\end{array}$ & $\begin{array}{c}\text { Shape } \\
\text { class }\end{array}$ & $\begin{array}{c}\text { Spore size } \\
(\mu \mathrm{m})\end{array}$ & $\begin{array}{l}\text { Spore } \\
\text { class }\end{array}$ \\
\hline \multicolumn{7}{|l|}{ Glecheniales } \\
\hline \multicolumn{7}{|l|}{ Glecheniaceae } \\
\hline Dicranopteris linearis & Monad, triangular, & Trilete, trichotomonosulcate, psilate & 1.20 & Subprolate & $35.25 \pm 0.66$ & Medium \\
\hline \multicolumn{7}{|l|}{ Polypodiales } \\
\hline \multicolumn{7}{|l|}{ Aspleniaceae } \\
\hline Asplenium nidus & Monad, reniform & Monolete, monosulcate, lophate & 0.77 & Suboblate & $37.74 \pm 1.02$ & Medium \\
\hline Asplenium longissimum & Monad, reniform & Monolete, monosulcate, costate & 0.66 & Oblate & $37.45 \pm 0.96$ & Medium \\
\hline \multicolumn{7}{|l|}{ Bleachnaceae } \\
\hline Stenochlaena palustris & Monad, reniform & Dilete, disulcate, verucate-rugulase & 0.67 & Oblate & $58.73 \pm 4.68$ & Large \\
\hline Blechnum serrulatum & Monad, reniform & Monolete, monosulcate, loosely cristate & 0.68 & Oblate & $34.95 \pm 0.76$ & Medium \\
\hline Blechnum sp. & Monad, reniform & Monolete, monosulcate, densely cristate & 0.72 & Oblate & $36.05 \pm 1.06$ & Medium \\
\hline \multicolumn{7}{|l|}{ Davalliaceae } \\
\hline Davallia denticulata & Monad, reniform & Monolete, monosulcate, verrucate & 0.60 & Oblate & $37.05 \pm 1.46$ & Medium \\
\hline \multicolumn{7}{|l|}{ Dennstaedtiaceae } \\
\hline Pteridium caudatum & Monad, triangular & Trilete, trichotomonosulcate, colliculate & 0.77 & Suboblate & $27.35 \pm 1.45$ & Medium \\
\hline \multicolumn{7}{|l|}{ Lindsaeaceae } \\
\hline Lindsaea ensifolia & Monad, triangular & Monolete, trichotomosulcate, rugulate & 0.95 & Spheroidal & $22 \pm 0.88$ & Small \\
\hline \multicolumn{7}{|l|}{ Nephrolepidaceae } \\
\hline Nephrolepis hirsutula & Monad, reniform & Monolete, monosulcate, verrucate & 0.91 & Spheroidal & $27.55 \pm 1.53$ & Medium \\
\hline Nephrolepis bisserata & Monad, reniform & Monolete, monosulcate, verrucate & 0.45 & Peroblate & $28.14 \pm 0.58$ & Medium \\
\hline \multicolumn{7}{|l|}{ Polypodiaceae } \\
\hline Microsorum pustulatum & Monad, reniform & Monolete, monosulcate, shallow verucate & 0.49 & Peroblate & $51.55 \pm 0.76$ & Large \\
\hline Pyrrosia piloselloides & Monad, reniform & Monolete, monosulcate, scabrate-echinate & 0.71 & Oblate & $53.8 \pm 1.81$ & Large \\
\hline $\begin{array}{l}\text { Phymatosorus } \\
\text { scolopendria }\end{array}$ & Monad, reniform & Monolete, monosulcate, rugulate & 0.52 & Oblate & $47.85 \pm 0.88$ & Medium \\
\hline \multicolumn{7}{|l|}{ Pteridaceae } \\
\hline Acrostichum aureum & Monad, triangular & Trilete, trichotomonosulcate, psilate & 0.55 & Oblate & $43.8 \pm 1.16$ & Medium \\
\hline $\begin{array}{l}\text { Ceratoptheris } \\
\text { thalictroides }^{\mathrm{b}}\end{array}$ & Monal, tetrahedral & Trilete, trichotomonosulcate canaliculate & - & - & 200 & Gigantic \\
\hline Pteris vitata & Monad, tetrahedral & $\begin{array}{l}\text { Trilete, trichotomonosulcate, thickened } \\
\text { cingulum with rugate and verrucate }\end{array}$ & 0.61 & Oblate & $51.34 \pm 1.83$ & Large \\
\hline Vittaria elongata $^{\mathrm{d}}$ & Monad, ellipsoidal & Monolete, finely undulate & & n.a. & $25-33$ & Large \\
\hline & & & & & $\begin{array}{l}52-63 \\
25-33\end{array}$ & \\
\hline Vittaria ensiformis ${ }^{\mathrm{c}}$ & Monad, reniform & Monolete & & n.a. & n.a. & \\
\hline \multicolumn{7}{|l|}{ Thelypteridaceae } \\
\hline Pronephrium sp. & Monad, reniform & Monolete, monosulcate, elongated flange & 0.66 & Oblate & $37.74 \pm 0.65$ & Medium \\
\hline \multicolumn{7}{|l|}{ Schizaeales } \\
\hline \multicolumn{7}{|l|}{ Lygodiaceae } \\
\hline Lygodium microphyllum & Monad, subtriangular & Trilete, trichotomonosulcate, orbiculate & 0.80 & Suboblate & $34.95 \pm 0.76$ & Medium \\
\hline Lygodium japonicum $^{\mathrm{d}}$ & Monad, subtriangular & Trilete, trichotomonosulcate, orbiculate & - & Spheroidal & $47-60 \times 60-63$ & large \\
\hline
\end{tabular}


Monad spore is more common in fern spore, compare to other spore types such as dyad, triad, tetrad or polyad. The basic spore types found in this study are monolete, dillete and trilete. Monolete has bean-shaped with elongated aperture (laesura) at proximal part (monosulcate laesura) (Regalado and Shanchez 2002). On the other hand, dilete has two elongated apertures (disulcate) (Sofiyanti et al. 2019a). While trilete spore has trichotomonosulcate laesura, in which laesure with three elongated arms, and joined in the middle (Traverse 2007). Monolete spore has reniform shape, this shape is plan-convex in equatorial view and on the other hand polar view has ecliptic shape (Regalado and Sanchez 2002). The shape class observed in this study based on Polar-Equatorial ration are peroblate, oblate, suboblate and spheroidal (Table 3). While the class of spore size follows Erdtman (1957), i.e. small (22 \pm 0.88 $\mu \mathrm{m})$, medium $(27.35 \pm 1.45$ to $47.85 \pm 0.88 \mu \mathrm{m})$ and large $(51.34 \pm 1.83$ to $53.8 \pm 1.81 \mu \mathrm{m})$. The important character of spore examined in this study is perisphore. This part is the outer spore surface and forms specific counter of spore that distinct within the species (Makgomol 2006).

\section{Glecheniales}

The only member of this order found in this study is Dicranopteris linearis (Gleicheniaceae). This species has monad spore type. The spore shape is triangular (Figure 3.A and 3.B) with trilete aperture or laesura and psilate perisphore The spore has equal shape and size on its angel (radial symmetry) with tetrahedral shape at proximal view (Figure 3.A), On the other hand, this species has triangular shape at equatorial view. These spore characters were also reported by Juhaz (1977), Perrie et al. 2012) and Jin et al. (2013). Dicranopteris linearis has medium spore class, with length of equatorial axis is $35.25 \pm 0.66 \mu \mathrm{m}$. The bigger size of spore $(50.44 \pm 5.23 \mu \mathrm{m})$ from this species was reported by Vijayakanth and Sathis (2016) (45 x 55 $\mu \mathrm{m})$ and Sofiyanti et al. (2019) and placed this spore in large spore. Their spore specimens were collected from different locations from this study, i.e. Khasmir (Vijayakanth and Sathis 2016) and Pekanbaru, Riau (Sofiyanti et al. 2019). However, the other spore characteristic, i.e. basic shape (trilete), laesura (trichotomnosulcate) and ornamentation (psilate) are the same as Dicranopteris linearis spore examined in this study. Trilete spore was also recorded from the fossil of other species within Gleicheniaceae e.g. Gleichenia bolanica. and Boodlepteris turoniana (Gandolfo et al. 1997)

The principal morphological features of trilete spore were described based on Traverse (2007). In this study, the length of laesura radii from radial area toward centre of Dicranopteris linearis is ca. $14.13 \pm 0.47 \mu \mathrm{m}$, with the thickness of commissure is $2.23 \pm 0.06 \mu \mathrm{m}$. Commissure is the centre of sulture. The torus or kyrtome thickness is 5.07 $\pm 0.47 \mu \mathrm{m}$. This area is an area beside the margin or raddi an often present as a folding feature. The labrum is curved area that well-known as suture lip, with $12.27 \pm 1.25 \mu \mathrm{m}$ length and $1.19 \pm 0.05 \mu \mathrm{m}$ wide. This species has $20.80 \pm$ $0.82 \mu \mathrm{m}$ interradial length. In polar proximal view, this area is the margin between two valvae.

\section{Polypodiales}

In this study, a total of 19 species within Polypodiales order was identified. However, 5 out of 19 species are juvenile individuals and do not reach maturity. Therefore, the spore characteristics could not be observed. The discussion of these 5 species was based on previous studies. A total of 9 families of Polypodiales order were recorded in this study. Our observation on the feature of spores indicated that the unity of spore is monad for all of the examined species.

Aspleniaceae. Species examined in this study were Asplenium nidus and A. longissimum. Morphologically, these species have different habits and leaf characteristics. However, the spore features are similar in spore unity (monad), shape (reniform), basic type (monolete) and aperture (monosulcate). The spore class is also the same i.e. medium spore class (ca. $37.4 \mu \mathrm{m}$ ). The medium spore class was also reported from other Asplenium species, such as $A$. monodon (Regalado and Sanchez 2002), A. antiquum, A. australium, A. grevelli as well as A. nidus (Wei and Dong (2012). The characteristic of each Aspleniaceae species examined in this study is perisphore ornamentation. $A$. nidus has lophate perisphore (Figure 4.A), while $A$. longissimum has costate perisphore (Figure 4.B). Lophate perisphore forms a winged fold structure, while costate perisphore has echinulate winged fold (Makgomol 2006). The spore grains of Asplenium are located inside the sporangium, that have bent sporangial annuus at distal part (Ekrt and Stech 2008) as seen in A. longissimum (Figure 3.B).

Blechnaceae. Fern species that belong to Blechnaceae family recorded in this study are Stenochlaena palustris, Blechnum serrulatum and Blechnum sp. The similarity of spore features within these species are found in spore unity (monad) and shape (reniform). The studies of Nayar et al. (1966) and Sofiyanti et al. (2019a) on spore of Stenochlaena palustris show dilete basic type with two elongated aperture along with the proximal view, known as disulcate. This species also has large spore class (58.73 \pm $4.68 \mu \mathrm{m}$ ) (Sofiyanti et al. 2019). These characters differ Stenochlaena palustris from Blechnum serrulatum and Blechnum sp. The study on other Stenochlaena species from Riau (Stenochlaena riauensis), reported the monolete and reniform shape at equatorial view (Sofiyanti et al. 2015). On the other hand, two species of Blechnum have monolete spore with only one aperture at proximal part (monosulcate). The spore class is medium on both species. However, the perisphore is different i.e. loosely cristate (Blechnum serrulatum) (Figure 4.C) and densely cristate (Blechnum sp.) (Figure 4.D). The other ornamentations were reported from Blechnum species i.e. verrucate, rugulate and perforate (Giacosa et al. 2009). 

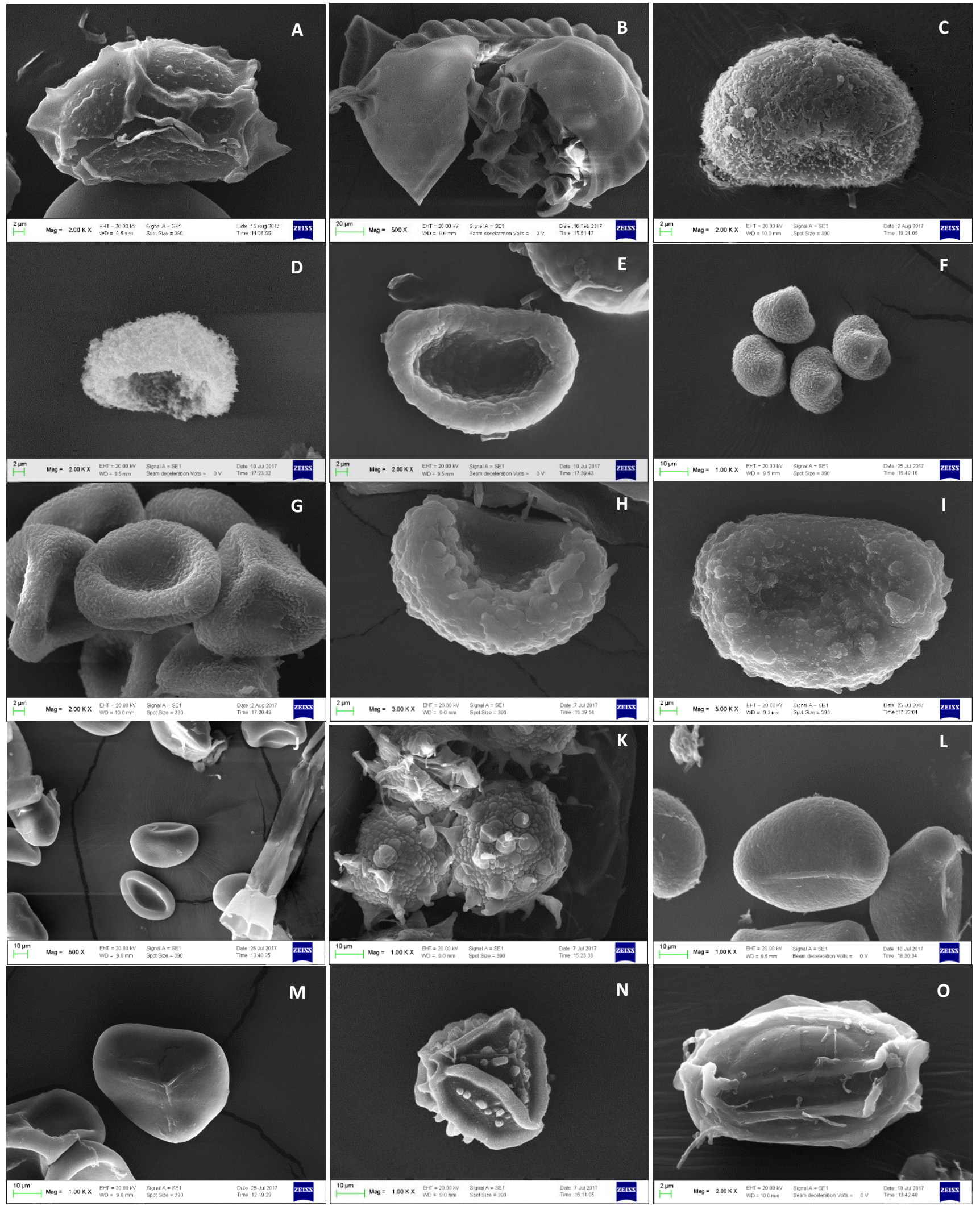

$\mathbf{N}$

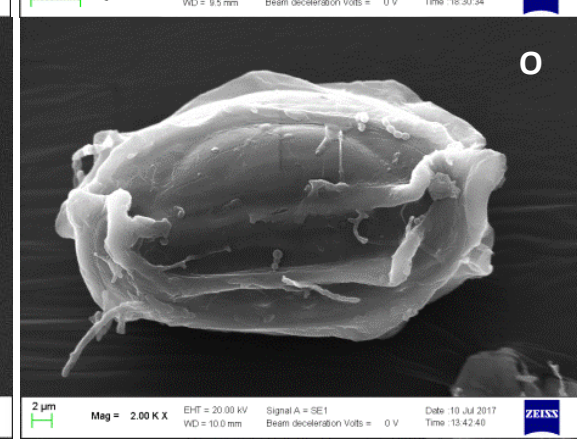

Figure 4. SEM image of Polypodiales spores of Bengkalis Island, Riau Province, Indonesia. A. Asplenium nidus (equatorial view showing lophate perisphore), B. Broken sporangium of Asplenium longissimus showing costate spore grains, C-D. Cristae spore (C. Blechnum serrulatum, D. Blechnum sp.), E. Davallia denticulata (Showing large and deep laesura), F. and G Trilete spore (F. Pteridium caudatum, G. Lindsaea ensiformis), H. Nephrolepis biserrata (Equatorial view), I. Neprolepis hirsutula (Proximal view), J. Microsorum punctatum, K. Phymatosorus scolopendria, L. Pyrrosia piloselloides (spore grain showing scabrate-echinate perisphore), M. Polar view of Acrostichum aureum spore, showing thin laesura and psilate perisphore. monolete grains, N. Pteris vitata (tetrahedral spore, showing thick cingulum, O. Phroneprium sp. (distal view, with elongated flanged perisphore) 
Davalliaceae. Davallia denticulata is the only species of Davalliaceae Family recorded in this study. This species has monad spore unity and reniform shape. The ornamentation of exospore is verucae conicullate. Figure 4.E shows large and deep laesura, with ellipsoidal shape of laesura, ca. $22 \times 10.5 \mu \mathrm{m}$ in size. This species has verrucae colliculate perisphore and medium spore class. The bigger size of spore was reported on the same species by Makgomol (2006), but the other characters are the same as Davallia species in this study. The verrucae perisphore is characteristic od Davallia species, as reported on $D$. napoensis, D. solida and D. formosa (Wang et al. 2011; 2014).

Denstaedtiaceae. The spore Pteridium caudatum is triangular shape in equatorial view (Figure 4.F) and tetrahedral shape on proximal view. Spores are trilete with trichotomonosulcate, and form commissure with linear and narrow arms. These characters were also recorded by Elżbieta (2012) on the same species. The ornamentation of perisphore is colliculate. This species has medium spore class (Table 3 ).

Lindsaeaceae. Lindsaea ensifolia has triangular shape in equatorial view, with tetrahedral shape on proximal view (Figure 4.G). The perisphore is rugulate, while spore class is small. The study of Makgomol (2006) reported medium spore class on this species. Another spore characteristic of Lindsaea ensifolia is thick and clearly seen laesura.

Nephrolepidaceae. We recorded two species of this family, i.e. Nephrolepis bisserata and N. hirsutula. These species have similar spore features. However, our observation on spore size, $N$. biserrata spores are smaller than $N$. hirsutula spores (Table 3 ). The perisphore of both species is verrucate (Figure 4.H and I). This structure was also reported on $N$. cordiofolia by Piñeiro and Morbelli (2012).

Polypodiaceae. Three members of this family, i.e. Microsorum pustulatum, Pyrrosia piloselloides, and Phymatosorus scolopendria have reniform spore shape in equatorial view, monolete basic type with monosulcate aperture. However, the ornamentations of perisphore and spore size are clearly distinct among the species observed. Microsorum pustulatum has psilate perisphore (Figure 4.J), while perisphore of Pyrrosia piloselloides and Phymatosorus scolopendria have scabrate-echinate (Figure 4.K) and rugulate ornamentation (Figure 4.L), respectively. Pyrrosia piloselloides has the biggest spore size among the other Polypodiaceae species observed in this study, the class of spore is large spore $(53.8 \pm 1.81 \mu \mathrm{m})$ and followed by Microsorum pustulatum $(51.55 \pm 0.76 \mu \mathrm{m})$. Therefore, both species have large spore class. The large spore class was also recorded on Microsorum pustulatum (Makgomol 2006), as well as on Pyrrosia lingua and Pyrrosia manii (Nayar and Devi 1964).

Pteridaceae. A total of five species in this family are recorded. However, only two species that had produced spore, i.e. Acrostichum aureum and Pteris vittata. These species have trilete basic spore types. Acrostichum aureum has triangular shape at equatorial view, with tetrahedral shape on proximal view, with very thin linear aperture (Figure 4.M). The length of aperture arm ca. 8-10 $\mu \mathrm{m}$. The length of laesura radii from radial area toward centre of this species is ca. 10-11 $\mu \mathrm{m}$, with the thickness of commissure is about $0.8 \mu \mathrm{m}$. The torus thickness is ca $2 \mu \mathrm{m}$, however, this area is not as clear as on Dicranopteris linearis spore. Pteris vittata has clear tetrahedral shape, trilete spore with trichotomonosulcate aperture The spore of this species is characterized by the presence of thickened and elongated cingulum along the margin with rugae and verrucae perisphore (Figure 4.N). The wide of cingulum is ca. 3-4.5 $\mu \mathrm{m}$. On the other hand, the aperture arm is very thin, ca. $0.7 \mu \mathrm{m}$, with $12-13 \mu \mathrm{m}$ long.

The spore description of Ceratopteris thalictroides, Vittaria elongata and Vittaria ensiformis was based on the previous study (Makgomol 2006; Marpaung et al. 2016). Ceratopteris thalictroides has very large spore and almost gigantic (ca. $200 \mu \mathrm{m}$ ) (Makgomol 2006). The spore is tetrahedral in equatorial view with canaliculate perisphore. While Vittaria has large spore with undulate perisphore (Marpaung et al. 2016).

Thelypteridaceae. Pronephrium spore is monolete, with elongated flanged perisphore along with the equatorial view (Figure 4.O). This species has medium spore class. The spore study on other Thelypteridaceae species was also recorded monolete type, on Christella dentata, Glaphyropteridopsis erubescens (subfamily Thelypteridoideae), and Phegopteris connectilis, Pseudophegopteris pyrrhorhachis, Pseudophegopteris levingei (subfamily Phegopteridoidea) (Shah et al. 2019).

\section{Schizaeales}

Lygodiaceae. the spore of Lygodium microphyllum Is presented in Figure 5. The distal view shows ellipsoidal shape (Figure 5.A). The slight equatorial view shows subtriangular shape (Figure 5.B) with psilate ornamentation on lower surface (indicated by arrow). The ornamentation of perisphore of this species is orbiculate that characterized by its small rounded structures or warts. The spore class of this species is medium. The large spore class of the Lygodium microphyllum from Thailand was recorded by Makgomol (2006). Most of the spore observations on other Lygodium were also reported the large spore, e.g. $L$. flexuosum, L. japonicum, L. polystachyum (Makgomol 2006), and L. hazaricum (Haq 2017). Most of Lygodium spore has anisomorphic. The study on Schizaeales spore from Riau Islands was reported by Sofiyanti et al. (2019b), i.e. Schizaea dichotoma (Schizaeaceae). In contrast with spore of Lygodiaceae species reported in this paper, the spore of Schizaea dichotoma is monolete with reniform shape at equatorial view. 

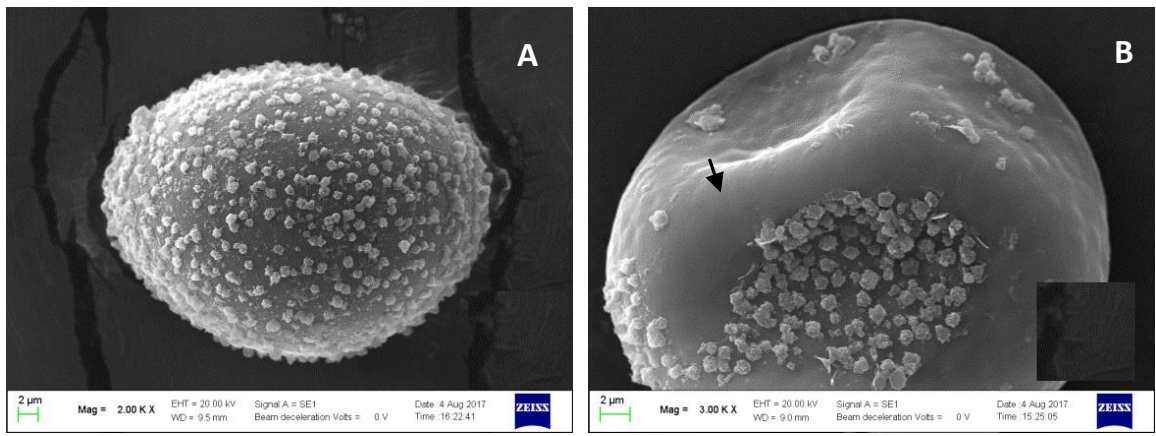

Figure 5. SEM image of Lygodium microphyllum spore (Schizaeales-Lygodiaceae) of Bengkalis Island, Riau Province, Indonesia. A. Distal part showing ellipsoidal shape, B. Equatorial view

The study of spore on ferns and its allies is important in taxonomic works. The spore characters can be used in taxa delimitation within a genus. In this study, most of the fern species have monolete spore type, compare to dilete or trilete spore. The spore class is dominated by medium class. The perisphore ornamentation within the species shows important taxonomic value. For ferns with trilete spore, the characteristics of trichotomonosulcate aperture also can be used to determine one species to its closely related.

\section{ACKNOWLEDGEMENTS}

The author thanks the Ministry of Research, Technology and Higher Education of the Republic of Indonesia for the Basic Research Grant.

\section{REFERENCES}

Al-Watban A, Al-Mogren E, Abdullah D, Mohamed E. 2013. Pollen morphology of seven wild species of Acacia in Saudi Arabia. Afr J Plant Scie 7: 602-607. DOI: 10.5897/AJPS2012.0989.

Chao YS, Huang YM. 2018. Spore morphology and its systematic implication in Pteris (Pteridaceae). PLoS ONE 13 (11): 1-22. DOI: https://doi.org/10.1371/journal.pone.0207712

Christenhusz MJM, Chase MW. 2014. Trends and concepts in fern classification. Ann Bot 113: 571-594. DOI:10.1093/aob/mct299.

de la Torre WW, Osorio VEM. 2013. Psilotum nudum (L.) P. Beauv. new species to the Canary Islands (Pteridophyta: Psilotaceae). Vieraea 41: 395-398.

Dettmann M, Clifford TH. 1991. Spore morphology of Anemia, Mohria, and Ceratopteris (Filicales). Am J Bot 78 (3): 303-325.

Ekrt L, Štech M. 2008. A morphometric study and revision of the Asplenium trichomanes group in the Czech Republic Morfometrická studie a revize komplexu Asplenium trichomanes v Preslia 80: 325 347.

Elżbieta Z. 2012. Morphology and peculiar features of spores of fern species occurring in Poland. Acta Agrobot 65: 3-10. 10.5586/aa.2012.053

Erdtman G. 1957. Pollen and spore morphology plant taxonomy: Gymnospermae, Pteridophyta, Bryophyta (illustrations). Almqvis and Wiksell, Stockholm. DOI: https://archive.org/details/pollensporemorph00erdt/page/n9.

Eric S, Kathleen P. 2007. Fern phylogeny inferred from 400 Leptosporangiate species and three plastid genes. Taxon 56: 1037 1050 .
Gandolfo M, Nixon KC, Crepet WL, Ratcliffe GE. 1997. A new fossil fern assignable to Gleicheniaceae from late Cretaceous sediments of New Jersey1. Am Jo Bot 84 (4): 483-493.

Giacosa RJP, Morbelli MA, Giudice GE. 2009. Spore morphology and wall ultrastructure of Blechnum L. species from North West Argentina. Rev Palaeobot Palynol 156 (1-2): 185-197. https://doi.org/10.1016/j.revpalbo.2008.11.002.

Haq F. 2017. Morpho-anatomical description of Lygodium hazaricum Haq a new contribution to the fern flora of Pakistan. Trop Plant Res 4 (2): 358-362, 2017. DOI: 10.22271/tpr.2017.v4.i2.047.

Hu S, David D, Harald S, Jarzen DM. 2006. Eusporangiate ferns from the Dakota formation, Minnesota, USA. Int J Plant Sci 167: 579-589.

Hugh C, Rolla T, David B. 2011. Development of the sorus in tree ferns: Dicksoniaceae. Can J Bot 76: 1245-1252. DOI: 10.1139/b98-122.

Jin XF, Ding BY, Iwatsuki K. 2013. Gleicheniaceae. Pp. 110-115 In Wu ZY, Raven PH, Hong DY (Eds) Flora of China, Vol. 2-3 (Pteridophytes). Missouri Botanical Garden Press, St. Louis.

Juhaz M. 1977. Gleicheniaceae spores from lower cretaceous deposits of Hungary. Acta Biol Szeged 23 (1-4): 3-17.

Kathleen P, Rothwell GW. 2001. Anatomically preserved Woodwardia virginica (Blechnaceae) and a new filicalean fern from the Middle Miocene Yakima canyon flora of Central Washington, USA. Am J Bot 88: 777-87. DOI: 10.2307/2657030.

Lashin GMA. 2012. Palynological studies of some species of Aspleniaceae-Pteridophyta. Am J Plant Sci 3: 397-402. http://dx.doi.org/10.4236/ajps.2012.33048.

Link-Perez M, Laffan SW. 2018. Fern and lycophyte diversity in the Pacific Northwest: Patterns and predictors. J Syst Evol 56 (5): 498522.

Makgomol K. 2006. Morphology of fern spores from Phu Phan National Park. Kasetsart J Nat Sci 40: 116-122.

Marpaung AA, Sofiyanti S, Iriani I. Morfologi spora paku Pteridaceae di Hutan PT. CPI Rumbai Riau. J Riau Biol 1 (2): 149-154. [Indonesian]

Nayar Bk, Bajpai N, Raza F. 1966. Morphological studies on some species of Blechnum, Doodia, Woodwardia and Stenochlaena: I. The gametophytes and the juvenile sporophytes. Bot J Linn Soc 59 (380): 405-423. DOI: https://doi.org/10.1111/j.1095-8339.1966.tb00071.x.

Nayar BK, Devi S. 1964. Spore morphology of Indian ferns. Grana Palynologica 5: 3, 342-395, DOI: 10.1080/00173136409430025.

Perrie LR, Shepherd, Brownsey PJ. 2012. Gleichenia inclusisora, a new and uncommon tangle fern from New Zealand. N Z J Bot 50 (4): 401410 .

Piggott AG. 1998. Fern of Malaysia in Color. Tropical Press Sdn.Bhd., Malaysia.

Piñeiro PM, Morbelli M. 2012. Spore morphology and wall ultrastructure in Nephrolepis cordifolia (Davalliaceae) from North-West Argentina. Bole Soc Argent Bot 47: 71-75.

Pryer KM, Schuetrpelz, R, Wolf PG, Schneider H, Smith AR, Cranfill R. 2004. Phylogeny and evolution of ferns (monilophytes) with a focus on the early Leptosporangiate divergences. Am J Bot 91 (10): 15821598.

Pšenička J, Jiří B, Christopher C, Jack W, Erwin Z. 2009. Description of synangia and spores of the holotype of the carboniferous fern Lobatopteris miltoni, with taxonomic comments. R Palaeobot Palynol 155: DOI: 10.1016/J.Revpalbo.2007.12.005 
Reddy S, Reddy AM, Yasodamma N. 2012. Exploration of wild ornamental flora of Ysr District, Andhra Pradesh, India. Indian J Fundam Appl Life Sci 2: 2231-6345.

Regalado R, Sánchez C. 2002. Spore morphology as a taxonomic tool in the delimitation of three Asplenium L. species complexes (Aspleniaceae: Pteridophyta) in Cuba, Grana. 41 (2): 107-113. DOI: 10.1080/001731302760156909.

Salamah A, Luthfikasari R, Dwiranti A. 2019. Pollen morphology of eight tribes of Asteraceae from Universitas Indonesia Campus, Depok, Indonesia. Biodiversitas 20 (1): 152-159.

Shah S, Mushtaq A, Muhammad Z, Fazal U, Wajid Z, Khafsa M, Neelam R, Saba G. 2019. Taxonomic importance of spore morphology in Thelypteridaceae from Northern Pakistan. Microsc Res Tech 82: 1326-1333. DOI: https://doi.org/10.1002/jemt.23283

Schuettpelz E, Pryer KM. 2007. Fern phylogeny inferred from 400 leptosporangiate species and three plastid genes. Taxon 56: 1037 1050 .

Sofiyanti N, Iriani D, Fimawati, Roza AA. 2015. Stenochlaena riauensis (Blechnaceae), a new fern species from Riau, Indonesia. Bangladesh J Plant Taxon 22 (2): 137-141.

Sofiyanti N, Iriani D, Fitmawati, Marpaung AA. 2019a. Morphology, palynology, and stipe anatomy of four common ferns from Pekanbaru, Riau Province, Indonesia. Biodiversitas 20 (1): 327-336. DOI: 10.13057/Biodiv/D200138.

Sofiyanti N, Iriani D, Ftmawati. 2019b. The first record of grass-like fern, Schizaea dichotoma (L.) J. Sm. (Schizaeaceae) from Lingga Island, Indonesia: Its morphological, anatomical and palynological study. Biodiversitas 20 (9): 2651-2660. DOI: 10.13057/Biodiv/D200930.

Sofiyanti N, Isda, MN. 2018. Kajian morfologi dan mikromorfologi (sisik serta trikoma) 4 jenis Pyrrosia Mirb. (Polypodiaceae) di Provinsi Riau. J Biol Trop 18 (2): 174-181. DOI: 10.29303/jbt.v18i2.857 [Indonesian]

Sofiyanti N, Isda, MN. 2019a. Jenis-jenis tumbuhan paku (Pteridofita) dari hutan Universitas Riau, Provinsi Riau dan pola pita DNA berdasarkan penanda DNA M13Primer. J Biospecies 12 (1): 24-32. [Indonesian]

Sofiyanti N, Isda, MN. 2019b. Paku kawat Lycopodiella cernua (L.) Pic. Serm. (Lycopdiaceae-Lycopodiales) dari Provinsi Riau-Kajian morfologi dan sekuen DNA berdasarkan primer RBCL. Jurnal Biologi Universitas Andalas 7 (1): 43-50. [Indonesian]

Sofiyanti N, Yen C. 2012. Morphology of ovule, seed and pollen grain of Rafflesia R. Br. (Rafflesiaceae). Bangladesh J Plant Taxon 19 (2): 109-117. https://doi.org/10.3329/bjpt.v19i2.13124.
Sofiyanti N. 2013. The diversity of epiphytic fern on the oil palm tree (Elaeis guineensis Jacq.) In Pekanbaru, Riau. J Biol 17 (2): 51-55.

Sofiyanti N. 2019. Aspleniaceae and Polypodiaceae from the coastal regions of Riau, Indonesia and their palynological study. Trop Plant Res 6 (2): 326-334, 2019. DOI: 10.22271/tpr.2019.v6.i2.042

Sutikno S, Sandhyavitri A, Haidar M, Yamamoto K. 2017. Shoreline change analysis of peat soil beach in Bengkalis Island based on GIS and RS. Int J Eng Technol Vol. 9, No. 3.

Traverse A. 2007. Spores/Pollen Morphology. In: Paleopalynology. Topics in Geobiology, vol 28. Springer, Dordrecht. DOI: https://doi.org/10.1007/978-1-4020-5610-9_5

Vasco A, Moran RC, Ambrose BA. 2013. The evolution, morphology, and development of fern leaves. Front Plant Sci 4 (345): 1-16.

Vijayakanth P, Sathish S. 2016. Studies on the spore morphology of pteridophytes from Kolli Hills, Eastern Ghats, Tamil Nadu, India. Int J Res Eng Biosci 4: 1-12.

Wang F, Chen H, Xing F. 2011. Davallia napoensis, a new species of Davalliaceae from Guangxi, China. Novon 21 (3): 380-384

Wang F, Liu H, He C, Yang D, Xing F. 2014. Taxonomic and evolutionary implications of spore ornamentation in Davalliaceae. $\mathbf{J}$ Syst Evol 53 (1): 73-81. DOI: 10.1111/jse.12115

Wang Y, Guignard G, Barale G. 1999. Morphological and ultrastructural studies on in situ spores of Oligocarpia (Gleicheniaceae) from the Lower Permian of Xinjiang, China. Int J Plant Scie 160 (5): 10351045 .

Wei L, Dong S. 2012. Taxonomic studies on Asplenium sect. Thamnopteris (Aspleniaceae) II: Spore morphology. Nord J Bot 30: 90-103.

White ME. 1981. Cylomeia undulata (Burges) gen. et comb. nov., a lycopod of the Early Triassic strata of New South Wales. Rec Austral Mus 33:723-734.

Wirdayanti, Sofiyanti N. 2019. Skrining fitokimia lima jenis tumbuhan paku Polypodiaceae dari Provinsi Riau. Biota 4 (2): 40-49. [Indonesian]

Wulandari D, Sofiyanti N, Fitmawati. 2016. Keanekaragaman jenis Polypodiaceae di hutan PT. CPI Rumbai Provinsi Riau berdasarkan karakter morfologi. J Riau Biol 1 (2): 135-139. [Indonesian]

Yusna M, Sofiyanti N, Fitmawati. 2016. Keanekaragaman Pteridaceae berdasarkan karakter morfologi dan fitokimia di hutan PT. Chevron Pacific Indonesia (PT. CPI) Rumbai. J Riau Biol 1 (2): 165-172. [Indonesian] 